\title{
Physiological and conjugated linoleic acid-induced changes of adipocyte size in different fat depots of dairy cows during early lactation
}

\author{
S. H. Akter, ${ }^{\star}$ S. Häussler, ${ }^{1}{ }^{1}$ S. Dänicke,† U. Müller, ${ }^{\star}$ D. von Soosten, $†$ J. Rehage,‡ and H. Sauerwein* \\ *Institute of Animal Science, Physiology and Hygiene Group, University of Bonn, 53115 Bonn, Germany \\ †Institute of Animal Nutrition, Friedrich-Loeffler-Institute (FLI), Federal Research Institute for Animal Health, 38116 Braunschweig, Germany \\ ¥Clinic for Cattle, School of Veterinary Medicine Hanover, 30173 Hanover, Germany
}

\section{ABSTRACT}

The aim of this study was to investigate the effects of lactation and conjugated linoleic acid (CLA) supplementation on adipocyte sizes of subcutaneous (s.c.) and visceral (VC) fat depots in primiparous dairy cows during the first $105 \mathrm{~d}$ in milk (DIM). German Holstein heifers $(\mathrm{n}=25)$ were divided into a control $(\mathrm{CON})$ and a CLA group. From 1 DIM until sample collection, CLA cows were fed $100 \mathrm{~g}$ of CLA supplement/d (about 6\% of $c 9, t 11$ and $t 10, c 12$ isomers each), whereas the $\mathrm{CON}$ cows received $100 \mathrm{~g}$ of fatty acid mixture/d instead of CLA. The CON cows $(\mathrm{n}=5$ each) were slaughtered at 1, 42, and 105 DIM, and the CLA cows ( $\mathrm{n}=5$ each) were slaughtered at 42 and 105 DIM. Adipose tissues from 3 s.c. depots (tailhead, withers, and sternum) and from $3 \mathrm{VC}$ depots (omental, mesenteric, and retroperitoneal) were sampled. Hematoxylin-eosin staining was done to measure adipocyte area $\left(\mu \mathrm{m}^{2}\right)$. Retroperitoneal adipocyte sizes were mostly larger than adipocytes from the other sites, independent of lactation time and treatment. Significant changes related to duration of lactation were limited to retroperitoneal fat: adipocyte sizes were significantly smaller at 105 DIM than at 1 DIM in CON cows. Adipocyte sizes were decreased in s.c. depots from the tailhead at 105 DIM and from the sternum at 42 DIM in CLA versus CON cows, whereas for $\mathrm{VC}$ depots, adipocyte sizes were decreased in mesenteric fat at 42 and 105 DIM, and in omental and retroperitoneal fat, at 105 DIM in CLA versus CON cows. Within the CLA group, adipocyte sizes were smaller in the s.c. depot from the tailhead at 105 DIM than at 42 DIM. Adipocyte sizes and depot weights were significantly correlated in s.c. depots $(\mathrm{r}=0.795)$ in the CLA group and in retroperitoneal fat both in the CON $(\mathrm{r}=0.698)$ and the CLA $(\mathrm{r}=0.723)$ group. In conclusion, CLA-induced decreases in adipocyte size indicate

Received September 28, 2010.

Accepted February 18, 2011.

${ }^{1}$ Corresponding author: susanne.haeussler@uni-bonn.de lipolytic or antilipogenic effects of CLA, or both effects, on adipose tissue in primiparous dairy cows.

Key words: adipocyte, conjugated linoleic acid, dairy cow, lactation

\section{INTRODUCTION}

The most metabolically stressful period in dairy cows is the early lactation, when milk production abruptly rises and an enormous metabolic drain is imposed on the body. The energy requirements at this period exceed the available energy from feed intake, resulting in a condition of negative energy balance (NEB). High-yielding dairy cows are then susceptible to various metabolic disorders and compromised immune response and fertility (Butler and Smith, 1989; Mallard et al., 1998). To meet the nutritional demands of milk synthesis, dairy cows need to mobilize body reserves (Bauman and Elliot, 1983). When the decrease in body fat is refined (i.e., taking the share of different fat depots into consideration), the proportional change in different time intervals after calving is different when comparing the subcutaneous (s.c.) depots with different visceral (VC) depots (Butler-Hogg et al., 1985).

Conjugated linoleic acids (CLA) comprise a group of geometric and positional conjugated dienoic isomers produced during biological or industrial hydrogenation of linoleic acid (C18:2, n-6). Cis-9, trans-11 $(\boldsymbol{c 9} \mathbf{9}, \boldsymbol{t 1 1})$ is the predominant natural CLA isomer occurring exclusively in ruminant meat and milk; commercially available CLA preparations contain this isomer together with the trans-10, cis-12 $(\boldsymbol{t 1 0 , c 1 2})$ isomer in equimolar concentrations (Poirier et al., 2006). Conjugated linoleic acids have attracted considerable attention because of their antiobesity, anticarcinogenic, antiatherogenic, antidiabetogenic, and immunomodulating properties in certain animal models (Belury, 2002; McLeod et al., 2004). Dietary CLA supplementation alters lipid metabolism and causes a decrease in milk fat secretion in lactating animals (Loor and Herbein, 1998; Ringseis et al., 2004). The $t 10, c 12$ isomer has been reported to be specific for the mammary gland and responsible for 
the decreased milk fat synthesis in lactating dairy cows (Baumgard et al., 2001), whereas the $c 9, t 11$ isomer had less effect (Perfield II et al., 2007). Nevertheless, the $t 10, c 12$ isomer causes a decreased body fat accretion in growing animals by decreasing de novo lipogenesis (Bauman et al., 2000). In addition, dietary CLA supplementation has been found to decrease body fat mass in several monogastric species, such as in pigs (Ostrowska et al., 1999), mice (Poirier et al., 2005; Halade et al., 2010), and also in obese humans (Blankson et al., 2000). Studies with bovine preadipocyte culture suggest that the $t 10, c 12$ isomer inhibited differentiation of preadipocytes to mature adipocytes (House et al., 2005; Smith et al., 2009; Lengi and Corl, 2010). Moreover, CLA-induced decrease in body fat mass in rats was due to a decrease in adipocyte size, rather than adipocyte number (Azain et al., 2000). However, CLA supplementation seemed to leave body fat unaffected because BCS and NEFA and leptin concentrations were not different from those of untreated controls $(\mathbf{C O N})$, at least when using relatively short treatment periods in dairy cows (Baumgard et al., 2002; Kay et al., 2006). To our knowledge, no report about body fat-decreasing effects of CLA in dairy cows exists, but more detailed histological studies of adipose tissues, in particular addressing the heterogeneity of s.c. versus VC fat depots, are lacking. Therefore, we assessed the mean adipocyte areas $\left(\mu \mathrm{m}^{2}\right)$ of s.c. and VC to characterize 6 different fat depots in terms of adipocyte size and to investigate 1) what physiological changes in adipocyte size of different fat depots occur in primiparous dairy cows during the first 105 DIM, and 2) whether and to what extent a rumen-protected CLA supplement changes the adipocyte size of different fat depots in dairy cows.

\section{MATERIALS AND METHODS}

\section{Animals, Diets, and Treatments}

The animal experimentation was done according to the European Union Guidelines and was approved by the Lower Saxony State Office for Consumer Protection and Food Safety (LAVES, File No. 33.11.4250204-071/07), Oldenburg, Germany. The experimental design and main results with regard to performance and body composition are described elsewhere (von Soosten et al., 2010). In brief, German Holstein heifers ( $\mathrm{n}=$ 25) with a mean BCS of 3.0 were housed in a freestall barn at the Experimental Station of the Institute of Animal Nutrition, Friedrich-Loeffler-Institute (FLI), Braunschweig, Germany. The cows were fed according to the recommendations of the German Society of Nutrition Physiology (GfE, 2001). Water was provided ad libitum. Before parturition, cows received a diet consisting of a partial mixed ration (PMR; $60 \%$ corn silage and $40 \%$ grass silage, $6.7 \mathrm{MJ}$ of $\mathrm{NE}_{\mathrm{L}} / \mathrm{kg}$ of $\mathrm{DM}$ ) on a DM basis ad libitum and $2 \mathrm{~kg}$ of concentrate/d (6.7 MJ of $\mathrm{NE}_{\mathrm{L}} / \mathrm{kg}$ of $\mathrm{DM}$ ). The feed ingredients and chemical composition of the postpartum diets fed from parturition until slaughter with the fatty acid profiles of the fat supplements used are shown in Table 1.

The cows were randomly allocated to either the CON $(\mathrm{n}=15)$ or the CLA $(\mathrm{n}=10)$ group. From 1 DIM until sample collection, the CLA cows were fed $100 \mathrm{~g}$ of rumen-protected CLA (Lutrell Pure; BASF, Ludwigshafen, Germany) per d, containing equal proportions of each of the $c 9, t 11$ and $t 10, c 12$ isomer. The pelleted CLA-concentrate contained about $6 \%$ each of the CLA isomers (calculated proportion in the CLA-concentrate; D. von Soosten, unpublished data). For the CON group, CLA were substituted by $100 \mathrm{~g}$ of an analogous fatty acid mixture (Silafat; BASF). The CON cows ( $\mathrm{n}=5$ each) were slaughtered at 1, 42, and 105 DIM, whereas the CLA cows $(\mathrm{n}=5$ each) were slaughtered at 42 and 105 DIM. Energy balance was calculated according to the recommendations of the German Society of Nutrition Physiology (GfE, 2001).

\section{Measurements and Sample Collection}

At slaughter, adipose tissue samples from s.c. and VC depots were immediately excised from the cows. Adipose tissues from 3 s.c. depots (tailhead, withers, and sternum) and from $3 \mathrm{VC}$ depots (omental, mesenteric, and retroperitoneal) were sampled. The mesenteric fat was collected from the fat around the jejunum and the retroperitoneal fat was sampled from the pararenal fat, located superficial to the renal fascia. All adipose tissue depots were then dissected and weighed. Milk samples were taken twice per week. Blood was collected in Vacutainer tubes containing sodium heparin or potassium EDTA (Becton Dickinson Vacutainer Systems USA, Rutherford, NJ) on the day of slaughter by venipuncture before slaughtering. Blood samples were analyzed for plasma concentrations of NEFA and BHBA with commercial kits (NEFA-C, Wako Chemicals GmbH, Neuss and Ranbut, Randox Laboratories GmbH, Wülfrath, Germany). The empty BW (EBW) was calculated as the sum of the weights of all body parts of the cows, which were recorded during the slaughter process without claws cut off, ingesta, and content of urinary and gall bladder.

\section{Histomorphology}

Adipose tissue samples $(\mathrm{n}=150)$ were fixed in $4 \%$ paraformaldehyde (Roth, Karlsruhe, Germany) over- 
tor Company, Tokyo, Japan) connected to a computer. Adipocyte areas of 100 adipocytes from 5 randomly selected fields per section were measured using DISKUS software (4th version; Hilgers, Königswinter, Germany) and then averaged. The unit of mean adipocyte area was square micrometer $\left(\mu \mathrm{m}^{2}\right)$.

\section{Statistical Analyses}

Data for all variables (EBW, depot weight, adipocyte area, energy balance, and plasma NEFA and BHBA concentrations) were tested for normal distribution with the Kolmogorov-Smirnov test and for homogeneity of variances with the Levene test. Statistical analyses were made using general linear model (GLM) followed by a Bonferroni post-hoc test to compare the differences within the CON groups and within the fat depots of both CON and CLA groups. For GLM, significance was defined as $P<0.05$ and trends for physiological responses were declared at $P<0.10$. The Student's $t$-test was used to analyze the differences between the CON and the CLA group at 42 and 105 DIM as well as within the CLA group on the respective day. Therefore, the threshold for statistical significance was defined as $P<0.017$ after the Bonferroni $\alpha$-correction for multiple comparisons $(\mathrm{n}=3 ; \alpha=0.05 / 3=0.017)$. Pearson correlation coefficients were used to examine the relations between adipocyte sizes and depot weights of different adipose tissues, and between adipocyte sizes and plasma NEFA and BHBA concentrations, respectively. All analyses were done using SPSS software, version 17.0 (SPSS, Inc., Chicago, IL). Values are given as means \pm SEM.

\section{RESULTS}

The animals were in NEB at 1 DIM, whereas higher $(P<0.001)$ and positive $\mathrm{EB}$ values were reached in both groups by 42 and 105 DIM (Figure 1). Empty BW was not different between sampling day or groups; EBW was numerically lower at 42 DIM $(P<0.10)$ than at 1 DIM in CON cows and lower than at 105 DIM in both CON and CLA cows (Table 2). Comparing the different fat depot weights from 1, 42, and 105 DIM, differences $(P<0.05)$ were limited to the retroperitoneal depot for which 52 and $63 \%$ of the mass recorded at 1 DIM were reached at 42 and 105 DIM, respectively (Table 2). For all other depots, numerical decreases, not reaching the level of significance, were observed from 1 to 42 DIM. From 42 to 105 DIM, numerical, but insignificant, increases were noticed for s.c. and omental fat, but not for mesenteric fat in the CON cows. In CLA cows, all fat depots were consistently
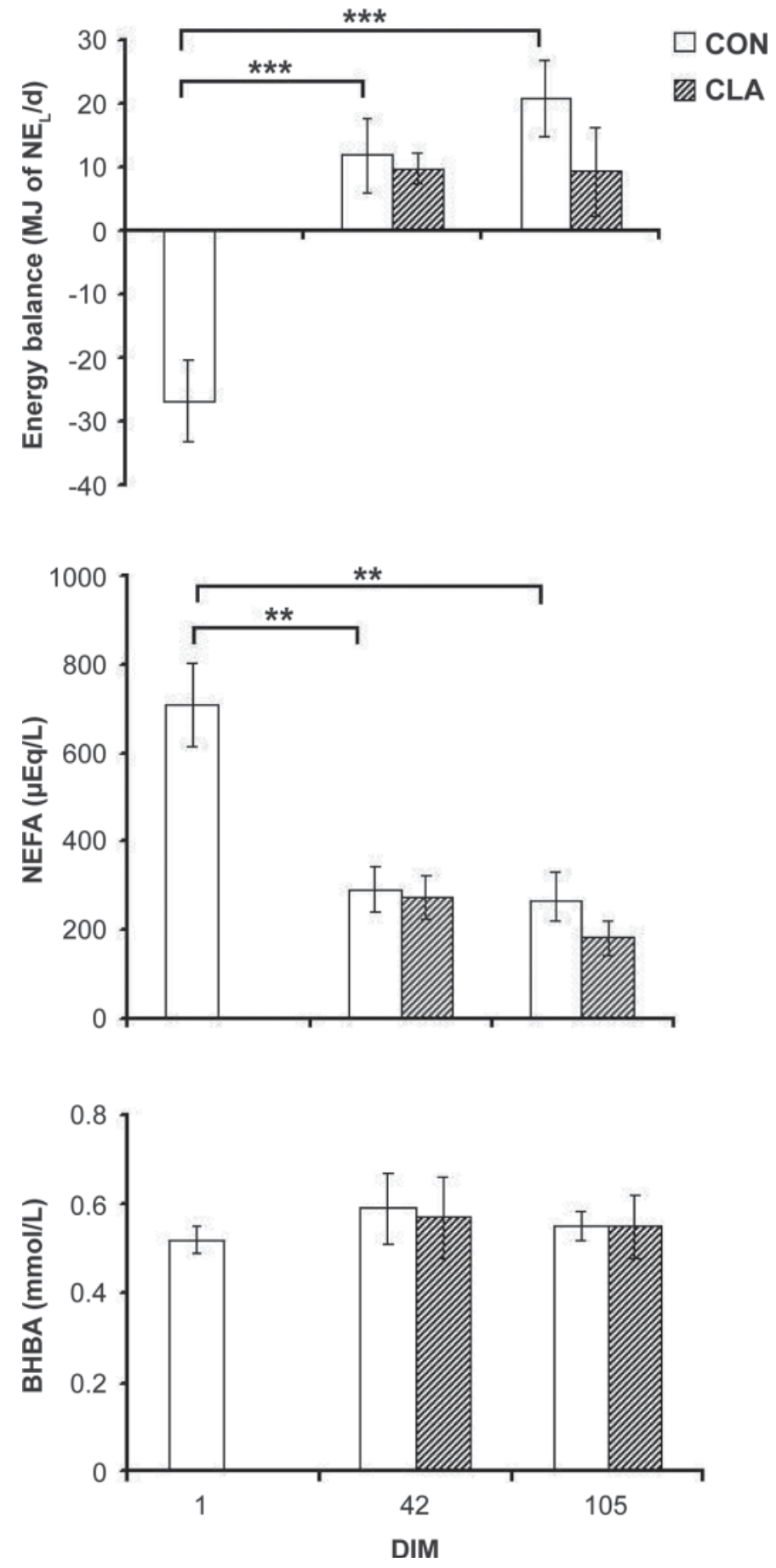

Figure 1. Energy balance and plasma concentrations of NEFA and BHBA of control (CON) and conjugated linoleic acid (CLA)supplemented dairy cows during the first 105 DIM. Each group represents the mean \pm standard error of the means of 5 animals. $* * P$ $<0.01 ; * * * P<0.001$. Net energy balance $\left(\mathrm{MJ}\right.$ of $\left.\mathrm{NE}_{\mathrm{L}} / \mathrm{d}\right)=$ energy intake $\left(\mathrm{MJ}\right.$ of $\left.\mathrm{NE}_{\mathrm{L}} / \mathrm{d}\right)-\left[\mathrm{NE}_{\mathrm{M}}\left(\mathrm{MJ}\right.\right.$ of $\left.\mathrm{NE}_{\mathrm{L}} / \mathrm{d}\right)+\mathrm{NE}_{\mathrm{L}}\left(\mathrm{MJ}\right.$ of $\left.\left.\mathrm{NE}_{\mathrm{L}} / \mathrm{d}\right)\right]$. 
Table 2. Empty BW (EBW; $\mathrm{kg}$ ) and different fat depot weights $(\mathrm{kg})$ in control $(\mathrm{CON})$ and conjugated linoleic acid (CLA)-supplemented dairy cows during the first 105 DIM

\begin{tabular}{|c|c|c|c|c|}
\hline \multirow[b]{2}{*}{ Item } & \multicolumn{3}{|c|}{ DIM } & \multirow[b]{2}{*}{$P$-value ${ }^{1}$} \\
\hline & 1 & 42 & 105 & \\
\hline \multicolumn{5}{|l|}{$\mathrm{CON}(\mathrm{n}=15 ;$ means \pm SEM $)$} \\
\hline EBW & $444 \pm 10.5$ & $395 \pm 12.4$ & $432 \pm 11.9$ & 0.052 \\
\hline \multicolumn{5}{|l|}{ Depot weight } \\
\hline Mean s.c. depot & $4.32 \pm 0.36$ & $3.29 \pm 0.40$ & $3.75 \pm 0.71$ & 0.481 \\
\hline \multicolumn{5}{|l|}{ Visceral (VC) depot } \\
\hline Omental & $11.0 \pm 1.04$ & $7.58 \pm 0.53$ & $8.53 \pm 1.21$ & 0.110 \\
\hline Mesenteric & $5.93 \pm 0.31$ & $4.97 \pm 0.39$ & $4.44 \pm 0.46$ & 0.094 \\
\hline Retroperitoneal & $8.76 \pm 0.87^{\mathrm{a}}$ & $4.58 \pm 0.65^{\mathrm{b}}$ & $5.56 \pm 1.01^{\mathrm{ab}}$ & 0.024 \\
\hline $\mathrm{CLA}(\mathrm{n}=10 ;$ means $\pm \mathrm{SEM})$ & & & & $-P$-value ${ }^{2}-$ \\
\hline EBW & & $399.3 \pm 10.94$ & $410.66 \pm 18.60$ & 0.650 \\
\hline \multicolumn{5}{|l|}{ Depot weight } \\
\hline Mean s.c. depot & & $4.86 \pm 0.83$ & $2.98 \pm 0.51$ & 0.123 \\
\hline \multicolumn{5}{|l|}{ VC depot } \\
\hline Omental & & $9.11 \pm 1.12$ & $7.40 \pm 1.06$ & 0.347 \\
\hline Mesenteric & & $5.87 \pm 0.68$ & $4.48 \pm 0.50$ & 0.184 \\
\hline Retroperitoneal & & $5.78 \pm 0.91$ & $4.27 \pm 0.87$ & 0.311 \\
\hline \multicolumn{5}{|l|}{ CON vs. CLA } \\
\hline EBW & & 0.836 & 0.418 & \\
\hline \multicolumn{5}{|l|}{ Depot weight } \\
\hline Mean s.c. depot & & 0.169 & 0.449 & \\
\hline \multicolumn{5}{|l|}{ VC depot } \\
\hline Omental & & 0.297 & 0.546 & \\
\hline Mesenteric & & 0.360 & 0.980 & \\
\hline Retroperitoneal & & 0.363 & 0.403 & \\
\hline
\end{tabular}

$\overline{\mathrm{a}, \mathrm{b}}$ Within a row, means with different superscript letters differ at $P<0.05$.

${ }^{1}$ General linear model followed by Bonferroni post-hoc tests; significant $P$-value $(P<0.05)$ is highlighted in boldface type.

${ }^{2}$ Student's $t$-test.

lighter at 105 versus 42 DIM, but again, the differences did not reach the level of significance (Table 2).

\section{Plasma NEFA and BHBA Concentrations}

In CON cows, plasma NEFA concentrations were higher at 1 DIM than at 42 DIM (2.4-fold; $P=0.01)$ and at 105 DIM (2.6-fold; $P=0.007)$, respectively. No differences existed in CLA versus CON groups and also within the CLA group (Figure 1). Concerning plasma BHBA concentrations, no differences were observed within the CON group, between the CON and the CLA group, or within the CLA group.

\section{Histomorphological Study}

Histomorphological examination revealed that the adipocytes were individually held in place by delicate reticular fibers clustering in lobules bounded by fibrous septa within the adipose tissue in both s.c. and VC depots. In s.c. depots, higher portions of connective tissue fibers were found than in VC depots (Figure 2). Typical, unilocular, signet ring-shaped adipocytes and small multilocular adipocytes were found in all of the fat depots examined. Small arteries and venules were present within the septa in all adipose tissues.

\section{Adipocyte Sizes of Different Fat Depots in CON and CLA Cows}

In CON cows, retroperitoneal adipocyte sizes were 1.4-fold larger $(P=0.01)$ than in s.c. depot from the sternum at 1 DIM (Table 3). Adipocyte sizes tended to be larger $(P<0.10)$ in retroperitoneal fat than that of s.c. depots from the tailhead and withers and of VC depot from mesenteric fat in CON cows at 1 DIM. The same trend $(P<0.10)$ for larger adipocyte size was also found in retroperitoneal fat when compared with s.c. depot from the withers in $\mathrm{CON}$ cows at 105 DIM. In CLA cows, retroperitoneal adipocyte sizes were 1.4-fold larger than those in s.c. depots from the withers $(P=0.041)$ and sternum $(P=0.037)$ at 42 DIM (Table 3). Representative pictures of an s.c. depot (from the tailhead) and also of a $\mathrm{VC}$ depot (retroperitoneal) are shown in Figure 2 for each treatment and sampling day. 


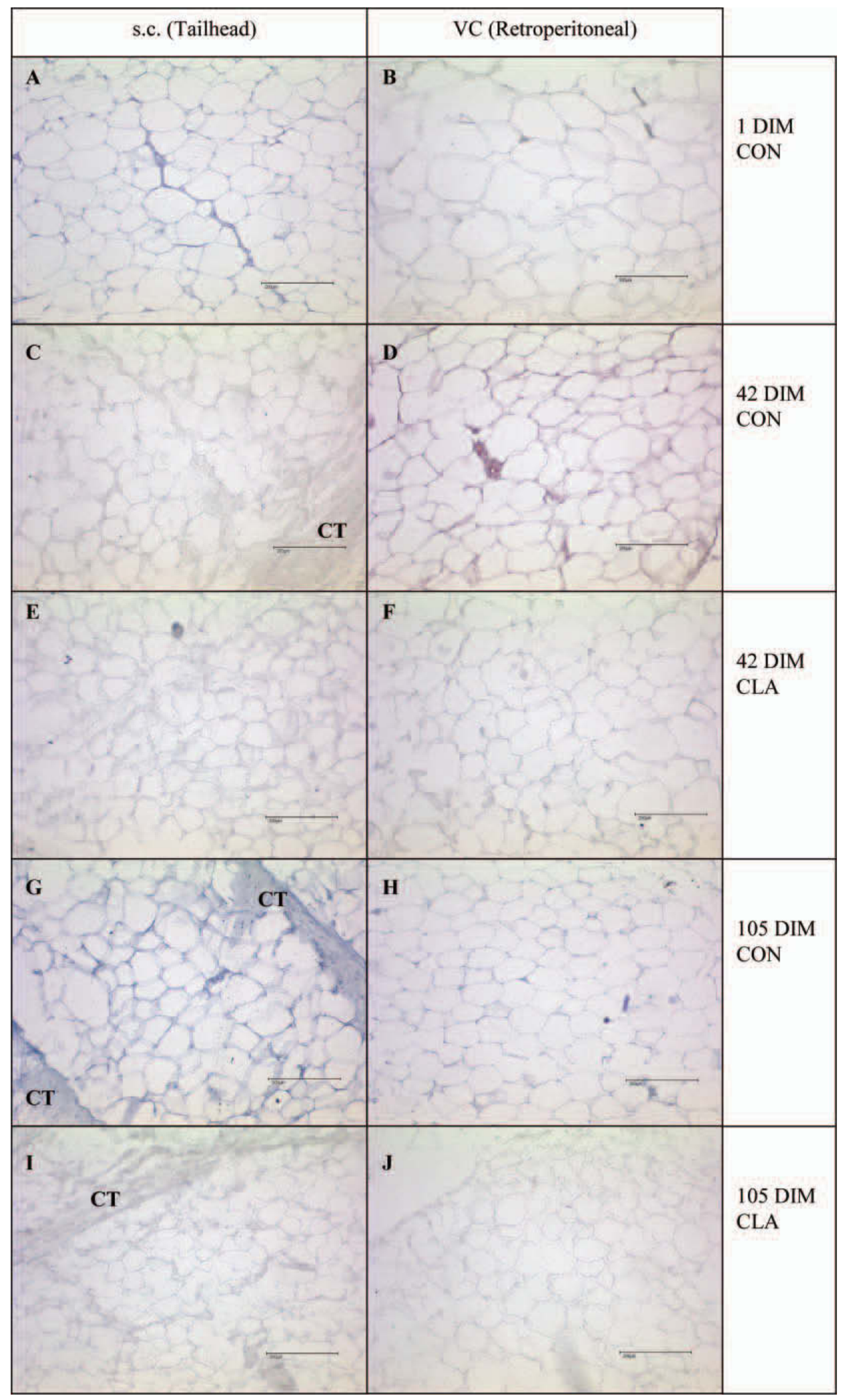

Figure 2. Histological sections of the s.c. fat depot from the tailhead (left column) and of the retroperitoneal visceral (VC) fat depot (right column) from control (CON) and conjugated linoleic acid (CLA)-supplemented dairy cows at 1, 42, and 105 DIM. Higher portions of connective tissue fibers were found in s.c. depots than in VC depots. Hematoxylin-eosin staining. Original magnification $100 \times$; scale bar $=200 \mu \mathrm{m} ; \mathrm{CT}=$ connective tissue fibers. Color version available in the online PDF. 
Table 3. Adipocyte sizes $\left(\mu \mathrm{m}^{2}\right)$ of different fat depots in control (CON) and conjugated linoleic acid (CLA)supplemented dairy cows during the first 105 DIM

\begin{tabular}{|c|c|c|c|c|}
\hline \multirow[b]{2}{*}{ Item } & \multicolumn{3}{|c|}{ DIM } & \multirow[b]{2}{*}{$P$-value ${ }^{1}$} \\
\hline & 1 & 42 & 105 & \\
\hline \multicolumn{5}{|l|}{$\mathrm{CON}(\mathrm{n}=15 ;$ means $\pm \mathrm{SEM})$} \\
\hline \multicolumn{5}{|l|}{ s.c. depot } \\
\hline Tailhead & $6,300 \pm 448^{\mathrm{ab}}$ & $5,442 \pm 408$ & $6,103 \pm 325$ & 0.389 \\
\hline Withers & $6,258 \pm 451^{\mathrm{ab}}$ & $5,110 \pm 407$ & $4,521 \pm 390$ & 0.060 \\
\hline Sternum & $5,782 \pm 243^{\mathrm{b}}$ & $5,180 \pm 314$ & $4,831 \pm 454$ & 0.257 \\
\hline \multicolumn{5}{|l|}{ Visceral (VC) depot } \\
\hline Omental & $6,381 \pm 372^{\mathrm{ab}}$ & $6,077 \pm 289$ & $5,851 \pm 286$ & 0.587 \\
\hline Mesenteric & $6,172 \pm 294^{\mathrm{ab}}$ & $6,222 \pm 267$ & $5,784 \pm 436$ & 0.682 \\
\hline Retroperitoneal & $7,945 \pm 208^{\mathrm{a}, \mathrm{y}}$ & $6,634 \pm 234^{\mathrm{yz}}$ & $6,500 \pm 414^{\mathrm{z}}$ & 0.019 \\
\hline CLA $(\mathrm{n}=10 ;$ means \pm SEM $)$ & & & & $P$-value \\
\hline \multicolumn{5}{|l|}{ s.c. depot } \\
\hline Tailhead & & $4,573 \pm 291^{\mathrm{ab}, \mathrm{y}}$ & $3,233 \pm 127^{\mathrm{z}}$ & 0.005 \\
\hline Withers & & $3,976 \pm 332^{\mathrm{b}}$ & $3,021 \pm 583$ & 0.239 \\
\hline Sternum & & $3,959 \pm 87^{\mathrm{b}}$ & $3,452 \pm 329$ & 0.220 \\
\hline \multicolumn{5}{|l|}{ VC depot } \\
\hline Omental & & $4,750 \pm 277^{\mathrm{ab}}$ & $3,997 \pm 410$ & 0.211 \\
\hline Mesenteric & & $4,235 \pm 296^{\mathrm{ab}}$ & $3,902 \pm 207$ & 0.433 \\
\hline Retroperitoneal & & $5,552 \pm 407^{\mathrm{a}}$ & $4,316 \pm 335$ & 0.070 \\
\hline \multicolumn{4}{|l|}{ CON vs. CLA } & \\
\hline \multicolumn{5}{|l|}{ s.c. depot } \\
\hline Tailhead & & 0.160 & 0.001 & \\
\hline Withers & & 0.090 & 0.092 & \\
\hline Sternum & & 0.010 & 0.059 & \\
\hline \multicolumn{5}{|l|}{ VC depot } \\
\hline Omental & & 0.018 & 0.011 & \\
\hline Mesenteric & & 0.002 & 0.008 & \\
\hline Retroperitoneal & & 0.074 & 0.006 & \\
\hline
\end{tabular}

${ }^{\mathrm{a}, \mathrm{b}}$ Within a column, means with different superscript letters differ at $P<0.05$.

${ }^{\mathrm{y}, \mathrm{z}}$ Within a row, means with different superscript letters differ at $P<0.05$ for general linear model (GLM) and $P<0.017$ for Student's t-test.

${ }^{1}$ GLM, followed by Bonferroni post-hoc tests; significant $P$-value $(P<0.05)$ is highlighted in boldface type.

${ }^{2}$ Student's $t$-test, after the Bonferroni $\alpha$-correction for multiple comparisons; significant differences $(P<0.017)$ are highlighted in boldface type.

\section{Influence of Lactation Time on Adipocyte Size During Early Lactation}

No effect of duration of lactation on adipocyte sizes of s.c. depots from the tailhead and sternum in CON cows was observed. Adipocyte sizes of s.c. depot from the withers in CON cows tended to be smaller $(P<$ $0.10)$ at 105 DIM than at 1 DIM (Table 3). Conversely, for VC depots, significant changes related to the duration of lactation were limited to retroperitoneal fat. In CON cows, retroperitoneal adipocyte sizes were 1.2-fold smaller $(P<0.05)$ at 105 DIM than at 1 DIM (Table $3)$, and tended to be smaller $(P<0.10)$ at 42 DIM than at 1 DIM. Moreover, no effect of duration of lactation on adipocyte sizes of omental and mesenteric fat depots was observed.

\section{Effects of CLA on Adipocyte Size During Early Lactation}

The s.c. depot from the tailhead had 1.9-fold smaller $(P=0.001)$ adipocyte sizes in CLA cows than in CON cows at 105 DIM, whereas s.c. depot from the sternum had 1.3-fold smaller $(P=0.01)$ adipocyte sizes in CLA cows than in CON cows at 42 DIM (Table 3 ). For VC depots, the adipocyte size was decreased 1.5-fold $(P$ $=0.011)$ in omental fat in CLA versus CON cows at 105 DIM. In mesenteric fat, adipocyte size was 1.5 -fold smaller in CLA cows than in CON cows, both at 42 DIM $(P=0.002)$ and 105 DIM $(P=0.008)$. Moreover, the adipocyte size of retroperitoneal fat was 1.5 -fold smaller $(P=0.006)$ in CLA versus CON cows at 105 DIM (Table 3). Within the CLA group, adipocyte size of s.c. depot from the tailhead was decreased 1.4-fold ( $P$ $=0.005$ ) from 42 to 105 DIM (Table 3). To assess the extent of CLA effects, percentage differences between adipocyte sizes of different fat depots of CON and CLA groups were calculated; for both sampling days, the corresponding CON group was taken as $100 \%$. Conjugated linoleic acid-supplemented cows had 16, 22, and $24 \%$ numerical decreases in adipocyte sizes in s.c. depots from the tailhead, withers, and sternum, respectively, compared with the CON cows at 42 DIM, whereas 47 , 
33 , and $29 \%$ numerical decreases in adipocyte sizes were observed in s.c. depots from the tailhead, withers, and sternum, respectively, in CLA cows compared with the CON cows at 105 DIM. For VC depots, the CLA cows had 22, 32, and $16 \%$ numerical decreases in adipocyte sizes in omental, mesenteric, and retroperitoneal fat, respectively, compared with the $\mathrm{CON}$ cows at 42 DIM, whereas 32,33 , and $34 \%$ numerical decreases in adipocyte sizes were observed in omental, mesenteric, and retroperitoneal fat, respectively, in CLA cows compared with the CON cows at 105 DIM.

\section{Correlations Between Adipocyte Sizes and Depot Weights of Different Adipose Tissues}

We examined the correlation between adipocyte areas and depot weights of s.c. and different VC depots at 1, 42, and 105 DIM. For the entire s.c. depot, the correlation was calculated between the mean adipocyte areas of all 3 s.c. depots examined and the weight of the entire s.c. fat. In CON cows, a strong positive correlation was found in retroperitoneal fat depot $(\mathrm{r}=$ $0.698, P=0.004, \mathrm{n}=15)$. In CLA cows, strong positive relationships were observed in the s.c. $\operatorname{depot}(\mathrm{r}=0.795$, $P=0.006, \mathrm{n}=10)$ and in the retroperitoneal depot $(\mathrm{r}$ $=0.723, P=0.018, \mathrm{n}=10$ ). Very strong relationships were found in the retroperitoneal depot both in CON (r $=0.905, P=0.035, \mathrm{n}=5)$ and CLA cows $(\mathrm{r}=0.892$, $P=0.042, \mathrm{n}=5)$ at 105 DIM.

\section{Correlations Between Adipocyte Sizes and Plasma NEFA and BHBA Concentrations}

We examined the correlation between adipocyte areas of different s.c. and VC depots and plasma NEFA and BHBA concentrations, respectively, at 1, 42, and 105 DIM. In CON cows, a strong positive correlation was found between retroperitoneal adipocyte sizes and plasma NEFA concentrations $(\mathrm{r}=0.698, P=0.004$, $\mathrm{n}=15$ ), whereas no significant relationships were detectable in any of the fat depots from the CLA cows (Table 4). A very strong inverse relationship was found between s.c. adipocyte sizes from withers and plasma NEFA concentration in CON cows at 42 DIM ( $\mathrm{r}=$ $-0.990, P=0.001, \mathrm{n}=5$ ). However, no significant relationships were found between adipocyte sizes and plasma BHBA concentrations in any of fat depots from the CON cows, whereas a strong positive correlation was found only in the s.c. depot from the sternum ( $\mathrm{r}$ $=0.651, P=0.041, \mathrm{n}=10)$ in CLA cows. Very strong positive relationships were found in the omental depot of CON cows $(\mathrm{r}=0.879, P=0.05, \mathrm{n}=5)$ and in s.c. depots from the tailhead $(\mathrm{r}=0.989, P=0.001, \mathrm{n}=5)$ and from the sternum $(\mathrm{r}=0.880, P=0.049, \mathrm{n}=5)$ of CLA cows at 105 DIM (Table 4).

\section{DISCUSSION}

The experimental primiparous cows experienced NEB on the first sampling day at 1 DIM, but were returned to positive EB on the day of the second slaughter series (i.e., 42 DIM), irrespective of CLA treatment. This is in contrast to the duration of NEB in pluriparous cows (Bauman and Currie, 1980). However, the trend for lower EBW at 42 DIM than at 1 DIM might reflect the effects of the preceding NEB; conversely, numerically higher EBW at 105 DIM than at 42 DIM may indicate the effects of positive EB in dairy cows, irrespective of CLA treatment (Table 2; Figure 1).

The size of adipocytes within an individual can vary considerably from depot to depot. It has been reported that the adipocytes from retroperitoneal fat have consistently larger adipocyte areas than the adipocytes from s.c., omental, and mesenteric fat depots in cows (Pike and Roberts, 1984). In the present study, we found that the adipocytes from retroperitoneal fat had significantly larger adipocyte areas than that of s.c. depot from the sternum in CON cows at 1 DIM. A tendency of increasing adipocyte size of retroperitoneal fat compared to that of s.c. depots from the tailhead and withers and of $\mathrm{VC}$ depot from mesenteric fat in $\mathrm{CON}$ cows at 1 DIM was observed. This could be related to metabolic differences between adipocytes from various depots, as known from monogastric species (Arner, 1998). Indeed, gene expression profiles from s.c. and VC fat depots in cattle (Hishikawa et al., 2005) support the notion of characteristic biochemical differences in these depots.

\section{Physiological Changes of Adipocyte Size During Early Lactation}

Bovine adipose tissue undergoes coordinated metabolic adaptations via a decrease in de novo lipogenesis and an increase in rates of lipolysis during early lactation (McNamara and Hillers, 1986). In the present study, we observed the physiological changes of adipocyte sizes of different fat depots during the first 105 DIM. Adipocytes from different regions have been reported to show a differential response during pregnancy and lactation in women, due to the condition of changing fat cell metabolism in different regions (Rebuffe-Scrive et al., 1985). Fat mobilization occurs in cows from late pregnancy through to midlactation, and the different depots respond to changing physiological states in different ways. Butler-Hogg et al. (1985) estimated from 
Table 4. Coefficients of significant correlations between adipocyte sizes of different fat depots and plasma concentrations of NEFA and BHBA in control (CON) and conjugated linoleic acid (CLA)-supplemented dairy cows during the first 105 DIM

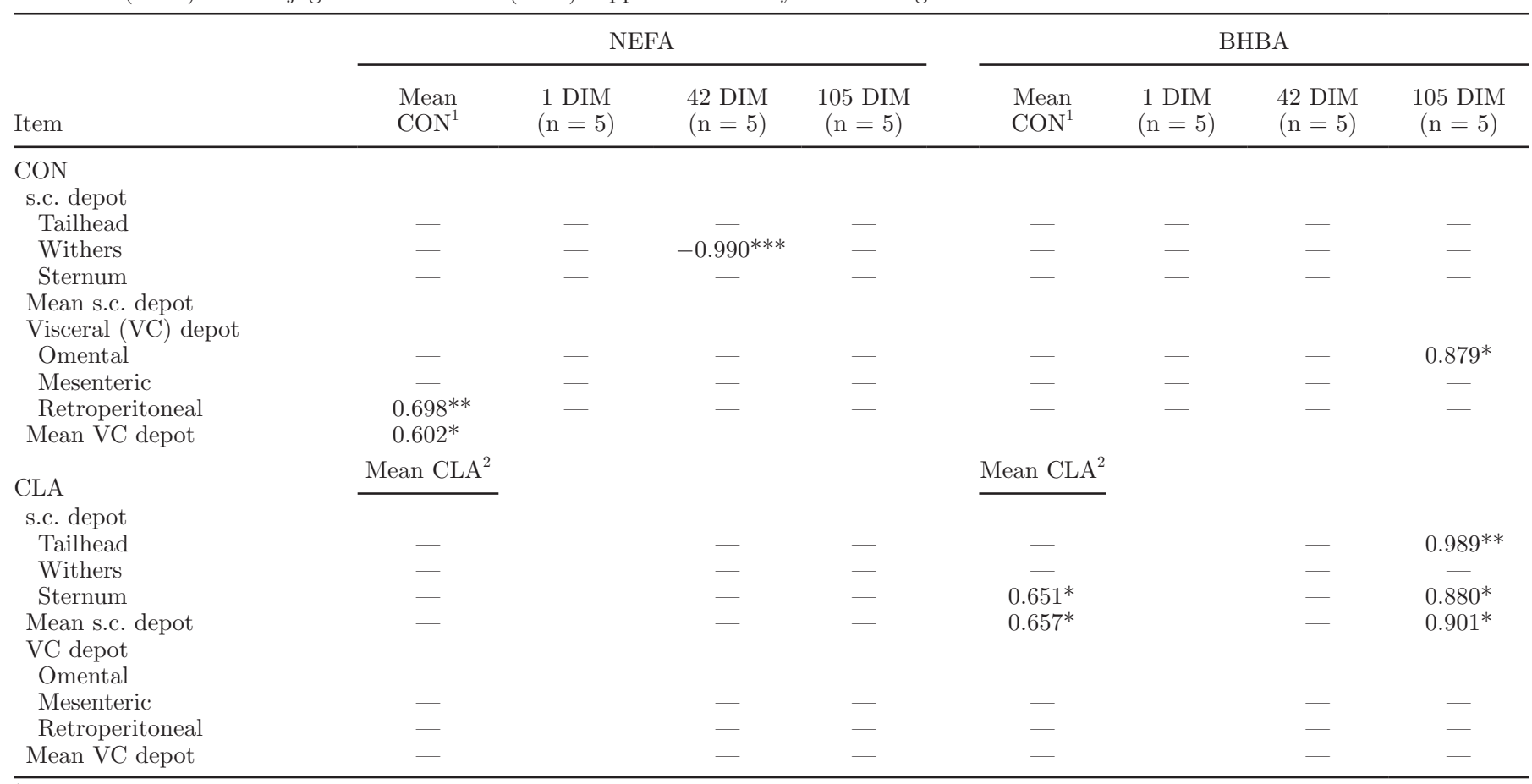

${ }^{1}$ Mean CON comprising the control fat-supplemented heifers from 1,42 , and 105 DIM $(\mathrm{n}=15)$.

${ }^{2}$ Mean CLA comprising the CLA-supplemented heifers from 42 and 105 DIM (n = 10).

${ }^{*} P \leq 0.05 ;{ }^{* *} P \leq 0.01 ;{ }^{* * *} P \leq 0.001$.

their dissection experiments that the rates of change on $\mathrm{a} \mathrm{g} / \mathrm{d}$ basis are highest from calving to peak lactation (42 DIM) in all depots whereby the intermuscular and the s.c. depots are the main contributors. Until midlactation (154 DIM), the rate of change in s.c. fat was only about $1 \%$ of the rate of change observed during the preceding period, whereas omental and mesenteric fat were further mobilized at 13 and $28 \%$ of the preceding rate. Perirenal retroperitoneal fat was not further decreased after peak lactation (Butler-Hogg et al., 1985). In our study, we found that the adipocyte size of retroperitoneal fat was 1.2-fold smaller in CON cows at 105 DIM than at 1 DIM, and also tended to be smaller at 42 DIM than at 1 DIM, suggesting that retroperitoneal fat was preferentially mobilized during peak-lactation. This finding is in agreement with the aforementioned study (Butler-Hogg et al., 1985). Moreover, the retroperitoneal fat depot weight was significantly decreased at 42 DIM and numerically decreased at 105 DIM compared with 1 DIM, suggesting that the retroperitoneal fat depot reacted most sensitively to the advancement of lactation.

Although significant changes related to duration of lactation were limited to retroperitoneal fat, data in Table 3 showed numerically decreased adipocyte size up to 105 DIM in almost all of the fat depots examined.
Active ongoing lipolysis, as evident from plasma NEFA concentrations, was thus, limited to the first sampling day at 1 DIM (Figure 1). This rapid rise in plasma NEFA concentration might be due to the stress of calving (Grummer, 1995). However, the time course of adipocyte decrease accompanying or following lipolysis or both, has not been characterized, at least to our knowledge. We, thus, speculate that the effects of lipolysis on adipocyte size were continued up to 105 DIM.

\section{CLA-Induced Changes of Adipocyte Size During Early Lactation}

The efficacy of the CLA supplementation in terms of milk fat decrease was confirmed in dairy cows during early lactation (D. von Soosten and S. Dänicke, unpublished data). We herein demonstrate for the first time CLA-induced changes of adipocyte size in dairy cows during early lactation. It has been reported that CLA decreased adipocyte size in rats, as to the significant decrease in mean adipocyte diameter (Sisk et al., 2001). The use of mean adipocyte diameter is an alternative method for estimating body fat and adipose tissue cellularity in lactating cows (Waltner et al., 1994).

The body fat-decreasing effects of CLA have also been reported in other studies in rats (Azain et al., 
2000; Noto et al., 2007) and pigs (Corino et al., 2005). Those studies were limited in that the adipocyte size was measured in only 1 fat depot (i.e., s.c.). DeLany et al. (1999) showed that dietary CLA supplementation decreased body fat accumulation in VC depots in mice. Poulos et al. (2001) found that CLA increased the proportion of smaller adipocytes and decreased the proportion of larger adipocytes of retroperitoneal fat depot in rat pups. In the present study, we observed that dietary CLA supplementation decreased adipocyte sizes of different s.c. and VC depots to different extents in dairy cows during the first 105 DIM. Moreover, the extent of CLA-induced decrease of adipocyte sizes is consistently higher at 105 DIM than at 42 DIM both for s.c. and VC depots, as indicated by the percent decreases. Specific regional metabolic differences that explain the differential regional response to CLA treatment are not well clarified. The regional differences could be explained by differences in accretion rates of different fat depots during the trial (Djian et al., 1983). It has also been reported that adipocytes in s.c. and VC depots show differences in basal metabolic properties, for example, in regulating volume and lipid composition as well as present differential gene expression profiles in humans (Montague et al., 1998) and cattle (Hishikawa et al., 2005). Within the CLA group, the adipocyte size significantly decreased only in s.c. depot from the tailhead, suggesting that the adipocyte size may not differ with the time of CLA supplementation.

\section{Mechanisms of Action of CLA}

The mechanisms behind a possible fat-decreasing effect of CLA are currently not well clarified. Both in vitro and in vivo studies in monogastric species demonstrated that CLA decreases adipocyte cellularity by decreasing adipocyte proliferation (Brodie et al., 1999; Evans et al., 2000) or adipocyte size (Azain et al., 2000; Evans et al., 2000; Brown et al., 2001). The t10,c12 isomer has been associated with decreased body fat mass in mice, whereas no such changes in body composition have been observed using the $c 9, t 11$ isomer (Park et al., 1999b). The t10,c12 isomer also induces adipocyte apoptosis in mice (Tsuboyama-Kasaoka et al., 2000). In addition, this CLA isomer decreases preadipocyte differentiation by downregulation of peroxisome proliferator-activated receptor gamma expression in humans (Brown and McIntosh, 2003). The CLA preparation used in the present study contained equal amounts of $c 9, t 11$ and $t 10, c 12$ isomers. The effects of CLA presented in this study could, therefore, result from either or both of these isomers.

The metabolic effects reported for CLA in adipose tissue suggest increased lipid mobilization, as evi- denced by increasing lipolysis and glycerol release, and decreased lipid deposition, as evidenced by decreasing activity of lipoprotein lipase (Park et al., 1997). These changes in lipid metabolism were exclusively associated with the $t 10, c 12$ isomer of CLA (Park et al. 1999b). The antilipogenic effect of CLA is accounted for by decreased lipid filling of adipocytes in CLA-supplemented rats (Azain et al., 2000). Decreased rates of lipogenesis have also been suggested to be the mechanism for the decrease in body fat accretion in CLA-supplemented humans (Brown et al., 2003), growing pigs (Ostrowska et al., 1999), and mice (Tsuboyama-Kasaoka et al., 2000). Thus, the effects of CLA on adipogenesis and lipid metabolism in animals are isomer-, dose-, time, and species-dependent (Evans et al., 2002). West et al. (1998) reported decreases in specific adipose tissue depots in male mice fed CLA, ranging from 40 to $80 \%$. Spalding et al. (2008) suggested that adipocyte number remains stable in adulthood in lean and obese individuals, although significant weight loss can result in a decrease in adipocyte volume; however, the decrease in body fat mass in response to CLA can be attributed to decreased adipocyte size, rather than adipocyte number (Azain et al., 2000). This basis for the decrease in fat mass is consistent with metabolic changes (decreased lipid deposition and increased lipolysis) and has been reported previously (Park et al., 1997, 1999a,b).

In contrast to the studies in monogastric species, whether, and to what extent, supplemental CLA dose changes the body fat in dairy cows has not yet been clarified. One mRNA expression study indicates that lipid synthesis is stimulated by short-term CLA supplementation in the adipose tissue of cows (Harvatine et al., 2009). Decreased rates of glucose utilization for lipid synthesis could be a mechanism by which CLA decrease body fat (Baumgard et al., 2002). However, in studies with shorter durations of CLA supplementation (up to 5 wk) than in our experiment, metabolic parameters and hormones, such as NEFA, glucose, insulin, and leptin, as well as BCS were not indicating any systemic changes in lipid metabolism and energy homeostasis (Baumgard et al., 2002; Kay et al., 2006; de Veth et al., 2006). In our present study, both plasma NEFA and BHBA concentrations were not different between CON and CLA groups. Moreover, a very strong inverse relationship was detectable in s.c. depot from withers in CON cows at 42 DIM, possibly indicating lipolysis during the physiological changes related to early lactation. Furthermore, both in vitro and in vivo bovine studies suggest that BHBA may play an important role in dairy cows for its feedback inhibitory effect on lipolysis (Metz et al., 1974). The receptor for BHBA [i.e., G-protein-coupled receptor109 (GPR109)] is predominantly expressed in adipose tissues of monogas- 
trics (Soga et al., 2003) and dairy cows (Lemor et al., 2009). Taggart et al. (2005) also reported that BHBA inhibits adipocyte lipolysis in mice via PUMA-G (also known as GPR109). Based on the positive correlation between adipocyte size and plasma BHBA from our present study, the processes of lipolysis might be increased in adipose tissues in a depot-specific manner both in CON- and CLA-supplemented cows. We, thus, speculate that lipolysis might be elevated during the physiological changes related to early lactation. In addition, the decreases in adipocyte size that we observed in CLA-supplemented cows may indicate lipolytic or antilipogenic effects of CLA, or both effects, on adipose tissue in primiparous dairy cows.

\section{CONCLUSIONS}

Significant physiological changes related to the duration of lactation were limited to retroperitoneal fat depot in CON cows during early lactation. Conjugated linoleic acid-induced decreases in adipocyte size in the present long-term study indicate that CLA does affect body fat in dairy cows similar to what is known from CLA-supplemented monogastrics. The present study suggested, for the first time, that dietary supplementation of CLA has site-specific effects on adipocyte size of different fat depots in dairy cows. These results may contribute to an improved and comprehensive assessment of CLA effects on animal health in dairy cows.

\section{ACKNOWLEDGMENTS}

This research was supported by the fund of the German Research Foundation (DFG, Bonn, Germany; Grant No. PAK 286/1, SA 432/10-1). S. H. Akter was the recipient of a Fellowship of the Islamic Development Bank (IDB) Merit Scholarship Program at the University of Bonn, Germany.

\section{REFERENCES}

Arner, P. 1998. Not all fat is alike. Lancet 351:1301-1302.

Azain, M. J., D. B. Hausman, M. B. Sisk, W. P. Flatt, and D. E. Jewell. 2000. Dietary conjugated linoleic acid reduces rat adipose tissue cell size rather than cell number. J. Nutr. 130:1548-1554.

Bauman, D. E., L. H. Baumgard, B. A. Corl, and J. M. Griinari. 2000. Biosynthesis of conjugated linoleic acid in ruminants. J. Anim. Sci. 77(Suppl. E):1-15.

Bauman, D. E., and W. B. Currie. 1980. Partitioning of nutrients during pregnancy and lactation: A review of mechanisms involving homeostasis and homeorhesis. J. Dairy Sci. 63:1514-1529.

Bauman, D. E., and J. M. Elliot. 1983. Control of nutrient partitioning in lactating ruminants. Pages 437-468 in Biochemistry of Lactation. T. B. Mepham, ed. Elsevier Sci. Publ., B. V., Amsterdam, the Netherlands.

Baumgard, L. H., B. A. Corl, D. A. Dwyer, and D. E. Bauman. 2002. Effects of conjugated linoleic acids (CLA) on tissue response to homeostatic signals and plasma variables associated with lipid metabolism in lactating dairy cows. J. Anim. Sci. 80:1285-1293.

Baumgard, L. H., J. K. Sangster, and D. E. Bauman. 2001. Milk fat synthesis in dairy cows is progressively reduced by increasing supplemental amounts of trans-10, cis-12 conjugated linoleic acid (CLA). J. Nutr. 131:1764-1769.

Belury, M. A. 2002. Dietary conjugated linoleic acid in health: Physiological effects and mechanisms of action. Annu. Rev. Nutr. 22:505-531.

Blankson, H., J. A. Stakkestad, H. Fagertun, E. Thom, J. Wadstein, and O. Gudmundsen. 2000. Conjugated linoleic acid reduces body fat mass in overweight and obese humans. J. Nutr. 130:2943-2948.

Brodie, A. E., V. A. Manning, K. R. Ferguson, D. E. Jewell, and C. Y. Hu. 1999. Conjugated linoleic acid inhibits differentiation of pre- and post-confluent 3T3-L1 preadipocytes but inhibits cell proliferation only in preconfluent cells. J. Nutr. 129:602-606.

Brown, J. M., M. S. Boysen, S. S. Jensen, R. F. Morrison, J. Storkson, R. Lea-Currie, M. Pariza, S. Mandrup, and M. K. McIntosh. 2003. Isomer-specific regulation of metabolism and PPAR $\gamma$ signaling by CLA in human preadipocytes. J. Lipid Res. 44:1287-1300.

Brown, J. M., Y. D. Halvorsen, Y. R. Lea-Currie, C. Geigerman, and M. McIntosh. 2001. Trans-10, cis-12, but not cis-9, trans-11, conjugated linoleic acid attenuates lipogenesis in primary cultures of stromal vascular cells from human adipose tissue. J. Nutr. 131:2316-2321.

Brown, J. M., and M. McIntosh. 2003. Conjugated linoleic acid in humans: Regulation of adiposity and insulin sensitivity. J. Nutr. 133:3041-3046.

Butler, W. R., and R. D. Smith. 1989. Interrelationships between energy balance and postpartum reproductive function in dairy cattle. J. Dairy Sci. 72:767-783.

Butler-Hogg, B. W., J. A. Wood, and J. A. Bines. 1985. Fat partitioning in British Friesian cows: The influence of physiological state on dissected body composition. J. Agric. Sci. (Camb.) 104:519-528.

Corino, C., A. Di Giancamillo, R. Rossi, and C. Domeneghini. 2005. Dietary conjugated linoleic acid affects morphofunctional and chemical aspects of subcutaneous adipose tissue in heavy pigs. J. Nutr. 135:1444-1450.

de Veth, M. J., E. Castañeda-Gutiérrez, D. A. Dwyer, A. M. Pfeiffer, D. E. Putnam, and D. E. Bauman. 2006. Response to conjugated linoleic acid in dairy cows differing in energy and protein status. J. Dairy Sci. 89:4620-4631.

DeLany, J. P., F. Blohm, A. A. Truett, J. A. Scimeca, and D. B. West. 1999. Conjugated linoleic acid rapidly reduces body fat content in mice without affecting energy intake. Am. J. Physiol. 276:R1172R1179.

Djian, P., A. K. Roncari, and C. H. Hollenberg. 1983. Influence of anatomic site and age on the replication and differentiation of rat adipocyte precursors in culture. J. Clin. Invest. 72:1200-1208.

Evans, M., J. Brown, and M. McIntosh. 2002. Isomer-specific effects of conjugated linoleic acid (CLA) on adiposity and lipid metabolism. J. Nutr. Biochem. 13:508-516.

Evans, M., C. Geigerman, J. Cook, L. Curtis, B. Kuebler, and M. McIntosh. 2000. Conjugated linoleic acid suppresses triglyceride accumulation and induces apoptosis in 3T3-L1 preadipocytes. Lipids 35:899-910.

GfE (German Society of Nutrition Physiology). 1991. Leitlinien für die Bestimmung der Verdaulichkeit von Rohnährstoffen an Wiederkäuern (Guidelines for determining the digestibility of crude nutrients in ruminants). J. Anim. Physiol. Anim. Nutr. (Berl.) 65:229-234

GfE (German Society of Nutrition Physiology). 2001. Ausschuss für Bedarfsnormen der Gesellschaft für Ernährungsphysiologie. Nr. 8. Empfehlungen zur Energie- und Nährstoffversorgung der Milchkühe und Aufzuchtrinder (Recommendations of energy and nutrient supply for dairy cows and breeding cattle). DLG-Verlag, Frankfurt am Main, Germany.

Grummer, R. R. 1995. Impact of changes in organic nutrient metabolism on feeding the transition dairy cows. J. Anim. Sci. 73:28202833 . 
Halade, G. V., M. M. Rahman, and G. Fernandes. 2010. Differential effects of conjugated linoleic acid isomers in insulin-resistant female C57Bl/6J mice. J. Nutr. Biochem. 21:332-337. doi:10.1016/j. jnutbio.2009.01.006.

Harvatine, K. J., J. W. Perfield II, and D. E. Bauman. 2009. Expression of enzymes and key regulators of lipid synthesis is upregulated in adipose tissue during CLA-induced milk fat depression in dairy cows. J. Nutr. 139:849-854.

Hishikawa, D., Y.-H. Hong, S.-G. Roh, H. Miyahara, Y. Nishimura, A Tomimatsu, H. Tsuzuki, C. Gotoh, M. Kuno, K. C. Choi, H. G. Lee, K. K. Cho, H. Hidari, and S. Sasaki. 2005. Identification of genes expressed differentially in subcutaneous and visceral fat of cattle, pig, and mouse. Physiol. Genomics 21:343-350.

House, R. L., J. P. Cassady, E. J. Eisen, M. K. McIntosh, and J. Odle. 2005. Conjugated linoleic acid evokes de-lipidation through the regulation of genes controlling lipid metabolism in adipose and liver tissue. Obes. Rev. 6:247-258.

Kay, J. K., J. R. Roche, C. E. Moore, and L. H. Baumgard. 2006. Effects of dietary conjugated linoleic acid on production and metabolic parameters in transition dairy cows grazing fresh pasture. J. Dairy Res. 73:367-377.

Lemor, A., A. Hosseini, H. Sauerwein, and M. Mielenz. 2009. Transition period-related changes in the abundance of the mRNAs of adiponectin and its receptors, of visfatin and of fatty acid binding receptors in adipose tissue of high-yielding dairy cows. Domest. Anim. Endocrinol. 37:37-44.

Lengi, A. J., and B. A. Corl. 2010. Factors influencing the differentiation of bovine preadipocytes in vitro. J. Anim. Sci. 88:1999-2008.

Loor, J. J., and J. H. Herbein. 1998. Exogenous conjugated linoleic acid isomers reduce bovine milk fat concentration and yield by inhibiting de novo fatty acid synthesis. J. Nutr. 128:2411-2419.

Mallard, B. A., J. C. Dekkers, M. J. Ireland, K. E. Leslie, S. Sharif, C. L. Vankampen, L. Wagter, and B. N. Wilkie. 1998. Alteration in immune responsiveness during the peripartum period and its ramification on dairy cow and calf health. J. Dairy Sci. 81:585-595.

McLeod, R. S., A. M. LeBlanc, M. A. Langille, P. L. Mitchell, and D. L. Currie. 2004. Conjugated linoleic acids, atherosclerosis, and hepatic very-low-density lipoprotein metabolism. Am. J. Clin. Nutr. 79(Suppl.):1169S-1174S.

McNamara, J. P., and J. K. Hillers. 1986. Adaptations in lipid metabolism of bovine adipose tissue in lactogenesis and lactation. J. Lipid Res. 27:150-157.

Metz, S. H. M., M. Lopes-Cardozo, and S. G. van den Bergh. 1974 Inhibition of lipolysis in bovine adipose tissue by butyrate and [beta]-hydroxybutyrate. FEBS Lett. 47:19-22.

Montague, C. T., J. B. Prins, L. Sanders, J. Zhang, C. P. Sewter, J. Digby, C. D. Byrne, and S. O'Rahilly. 1998. Depot-related gene expression in human subcutaneous and omental adipocytes. Diabetes 47:1384-1391.

Noto, A., P. Zahradka, N. Yurkova, X. Xie, H. Truong, E. Nitschmann, M. R. Ogborn, and C. G. Taylor. 2007. Dietary conjugated linoleic acid decreases adipocyte size and favorably modifies adipokine status and insulin sensitivity in obese, insulin-resistant rats. Metabolism 56:1601-1611.

Ostrowska, E., M. Muralitharan, R. F. Cross, D. E. Bauman, and F. R. Dunshea. 1999. Dietary conjugated linoleic acids increase lean tissue and decrease fat deposition in growing pigs. J. Nutr. 129:2037-2042.

Park, Y., K. J. Albright, W. Liu, J. M. Storkson, M. E. Cook, and M. W. Pariza. 1997. Effect of conjugated linoleic acid on body composition in mice. Lipids 32:853-858.

Park, Y., K. J. Albright, J. M. Storkson, W. Liu, M. E. Cook, and M. W. Pariza. 1999a. Changes in body composition in mice during feeding and withdrawal of conjugated linoleic acid. Lipids $34: 243-248$.

Park, Y., J. M. Storkson, K. J. Albright, W. Liu, and M. W. Pariza. 1999b. Evidence that the trans-10,cis-12 isomer of conjugated linoleic acid induces body composition changes in mice. Lipids $34: 235-241$.
Perfield, J. W. II, A. L. Lock, J. M. Griinari, A. Sæbø, P. Delmonte D. A. Dwyer, and D. E. Bauman. 2007. Trans-9, Cis-11 conjugated linoleic acid reduces milk fat synthesis in lactating dairy cows. J. Dairy Sci. 90:2211-2218.

Pike, B. V., and C. J. Roberts. 1984. Size and lipolytic capacity of bovine adipocytes from subcutaneous and internal adipose tissue. Vet. Res. Commun. 8:61-64.

Poirier, H., C. Rouault, L. Clement, I. Niot, M.-C. Monnot, M. Guerre-Millo, and P. Besnard. 2005. Hyperinsulinaemia triggered by dietary conjugated linoleic acid is associated with a decrease in leptin and adiponectin plasma levels and pancreatic beta cell hyperplasia in the mouse. Diabetologia 48:1059-1065.

Poirier, H., J. S. Shapiro, R. J. Kim, and M. A. Lazar. 2006. Nutritional supplementation with trans-10, cis-12-conjugated linoleic acid induces inflammation of white adipose tissue. Diabetes 55:1634-1641.

Poulos, S. P., M. Sisk, D. B. Hausman, M. J. Azain, and G. J. Hausman. 2001. Pre- and postnatal dietary conjugated linoleic acid alters adipose development, body weight gain and body composition in Sprague-Dawley rats. J. Nutr. 131:2722-2731.

Rebuffé-Scrive, M., L. Enk, N. Crona, P. Lönnroth, L. Abrahamsson, U. Smith, and P. Björntorp. 1985. Fat cell metabolism in different regions in women. Effect of menstrual cycle, pregnancy, and lactation. J. Clin. Invest. 75:1973-1976.

Ringseis, R., D. Saal, A. Müller, H. Steinhart, and K. Eder. 2004. Dietary conjugated linoleic acids lower the triacylglycerol concentration in the milk of lactating rats and impair the growth and increase the mortality of their suckling pups. J. Nutr. 134:33273334 .

Sisk, M. B., D. B. Hausman, R. J. Martin, and M. J. Azain. 2001. Dietary conjugated linoleic acid reduces adiposity in lean but not obese Zucker rats. J. Nutr. 131:1668-1674.

Smith, S. B., H. Kawachi, C. B. Choi, C. W. Choi, G. Wu, and J. E. Sawyer. 2009. Cellular regulation of bovine intramuscular adipose tissue development and composition. J. Anim. Sci. 87(Suppl.):E72-E82.

Soga, T., M. Kamohara, J. Takasaki, S. Matsumoto, T. Saito, T. Ohishi, H. Hiyama, A. Matsuo, H. Matsushime, and K. Furuichi. 2003. Molecular identification of nicotinic acid receptor. Biochem. Biophys. Res. Commun. 303:364-369.

Spalding, K. L., E. Arner, P. O. Westermark, S. Bernard, B. A. Buchholz, O. Bergmann, L. Blomqvist, J. Hoffstedt, E. Näslund, T. Britton, H. Concha, M. Hassan, M. Rydén, J. Frisén, and P. Arner. 2008. Dynamics of fat cell turnover in humans. Nature 453:783-787.

Taggart, A. K. P., J. Kero, X. Gan, T.-Q. Cai, K. Cheng, M. Ippolito, N. Ren, R. Kaplan, K. Wu, T.-J. Wu, L. Jin, C. Liaw, R. Chen, J. Richman, D. Connolly, S. Offermanns, S. D. Wright, and M. G. Waters. 2005. (D)- $\beta$-hydroxybutyrate inhibits adipocyte lipolysis via the nicotinic acid receptor PUMA-G. J. Biol. Chem. 280:26649-26652.

Tsuboyama-Kasaoka, N., M. Takahashi, K. Tanemura, H. J. Kim, T. Tange, H. Okuyama, M. Kasai, S. Ikemoto, and O. Ezaki. 2000. Conjugated linoleic acid supplementation reduces adipose tissue by apoptosis and develops lipodystrophy in mice. Diabetes 49:1534-1542

von Soosten, D., U. Meyer, G. Flachowsky, and S. Dänicke. 2010. Effect of rumen-protected conjugated linoleic acids (CLA) on adipose depot distribution and liver weight of dairy cows. Page 88 in Proc. Soc. Nutr. Physiol. (19), Göttingen, Germany. ISBN 978-37690-4103-3. DLG Verlag, Frankfurt am Main, Germany.

Waltner, S. S., J. P. McNamara, J. K. Hillers, and D. L. Brown. 1994 Validation of indirect measures of body fat in lactating cows. J. Dairy Sci. 77:2570-2579.

West, D. B., J. P. Delany, P. M. Camet, F. Blohm, A. A. Truett, and J. Scimeca. 1998. Effects of conjugated linoleic acid on body fat and energy metabolism in the mouse. Am. J. Physiol. 275:R667R672. 